\title{
IDENTIDAD MAYA Y GLOBALIZACIÓN
}

\author{
José O. Alejos García \\ Centro de Estudios Mayas, IIFL, UNAM
}

\section{Introducción}

Quiero iniciar agradeciendo a mis colegas del Centro de Estudios Mayas por el honor de asignarme la conferencia de clausura del evento que ahora nos reúne. ${ }^{1}$ Es una distinción que me ha significado un gran compromiso y responsabilidad, por colocarme en la situación de discutir directamente la temática general del congreso: la relación entre la naturaleza y las dinámicas sociales, y en especial la identidad maya en el contexto de la globalización. Como digo, es un tema central de debate, sobre el cual se han presentado excelentes trabajos, se han discutido asuntos tan importantes y diversos, que en esta clausura lo mío podría resultar redundante, o de menguado interés. Para colmo de males, debo reconocer que no soy especialista en el tema ni en otros conexos. Por ello, pido al amable lector su comprensión, y que vea éste como un ensayo, como una voz más que participa en este diálogo académico. Lo que en definitiva me acompaña e impulsa a participar en la discusión sobre el tema es el convencimiento de que los mayistas, humanistas y científicos sociales en general, debemos enfrentar, como lo están haciendo las sociedades y culturas que estudiamos, los retos que presenta el mundo actual.

He organizado la exposición en tres momentos: el primero es un intento por caracterizar al sistema social que genera la globalización. Ello requiere de una abstracción teórica que nos permita definir la lógica y funcionamiento del sistema, su manera de relacionarse con lo que considera "entorno", es decir, con las culturas "otras" y con el entorno ecológico. Para este fin discuto la teoría de sistemas de Niklas Luhmann, por considerar que es un importante paradigma científico de la sociedad moderna. En el segundo momento discuto el tema de la globalización, vinculado al concepto luhmanniano de modernidad, a fin de mostrar cómo el modelo teórico es llevado a la práctica por el sistema dominante. Por último, discuto diversos aspectos de identidad maya contemporánea, buscando entenderla en su relación con el modelo de la globalización. Se trata de comprender cómo la identidad indígena se construye dialógicamente, en la in-

\footnotetext{
${ }^{1}$ El presente artículo es una versión modificada de la conferencia de clausura dictada en el Sexto Congreso Internacional de Mayistas, celebrado en Villahermosa, Tabasco, en julio de 2004.
} 
teracción entre el nosotros y los otros, entre los mayas y el sistema social dominante.

\section{El sistema social}

Un revelador libro de Niklas Luhmann titulado Ecological Communication (1989) permitirá iniciar la discusión, pues su teoría del sistema social me parece de especial interés para un acercamiento al tema de la globalización. Antes quiero decir que soy consciente de que esta discusión teórica puede parecer abstracta, y hasta fuera de lugar en un congreso especializado de mayistas. En cambio, pude haber realizado un recuento de los efectos de la globalización en los pueblos mayas, y desprender de allí alguna conclusión, o pude haber presentado evidencia etnográfica de cómo los mayas se "globalizan". Pero considero que ocuparnos sólo de los efectos de este fenómeno puede llevarnos a conclusiones limitadas, o especulativas, sería una manera de viajar "entre las ramas", que aportaría poco a un entendimiento integral y profundo. Es por ello que me parece importante partir de un planteamiento teórico general, para conceptualizar con claridad el ambiente macrosocial donde los mayas encuentran no sólo un poderoso campo social en el interior del cual se construyen y "reinventan" sus identidades, sino también porque así, en un segundo momento del análisis, la cultura maya puede ser contrastada con el sistema social dominante, y valorada en términos de su diferencia específica y de su potencial propositivo para el mundo de hoy.

Luhmann es bien conocido en el campo de las ciencias sociales por su concepción teórica acerca del sistema social y la modernidad. Su libro Ecological Communication nos parece de gran importancia, tanto por la síntesis que presenta de la teoría general, como por su perspectiva sobre los problemas ecológicos en la modernidad. En términos de Luhmann, el problema de fondo consiste en la dificultad del sistema social para tratar con su "entorno", ${ }^{2}$ es decir, en la manera como la sociedad moderna se relaciona con el medio ambiente natural y con sociedades y culturas "otras". Llámese a éstas "arcaicas", "tradicionales", "indígenas" o "tercermundistas", aquellas que al ser externas al sistema socia,l son asumidas por éste como "entorno", como elementos exógenos carentes de significado, que sólo son tomados en cuenta si logran producir "resonancia", una irritación en el sistema, un "ruido" que lleve al sistema a conceptualizarlos y convertirlos en un tema de la comunicación interna. En otras palabras: el problema consiste en la sordera e indiferencia del sistema social respecto a todo aquello que le es ajeno, que no existe como parte de su código comunicativo. $^{3}$

\footnotetext{
${ }^{2}$ Environment en el texto de referencia.

${ }^{3}$ Sonesson (2002) subraya el carácter de modelo cultural de la globalización y plantea, desde
} 
El punto clave de la teoría de sistemas de Luhmann es la autopoiesis, concepto tomado de la biología, que el autor refiere como la capacidad de los sistemas vivientes de mantener su autonomía y unidad mediante sus propias operaciones. Se trata de aquellos sistemas que reproducen todos los componentes elementales que lo han conformado, por medio de una articulación de esos mismos componentes, distinguiéndose de esa manera del entorno (op. cit.: 143). El movimiento que realiza Luhmann es aplicar esta noción del sistema autopoiético al campo de la teoría social, de donde ha derivado un poderoso aparato teórico que permite dar cuenta de la sociedad moderna y, en consecuencia, de la situación de las sociedades otras y del mundo natural respecto de aquélla. Escuchemos su argumentación:

La autopoiesis significa el cierre de la organización de un sistema, es decir, la auto-referencia de un complejo de componentes y de procesos productores de componentes que se reproducen mutuamente y que por lo mismo integran y unifican al sistema. El cierre organizacional no significa que un sistema no pueda ser afectado del todo por su entorno. Pero sí significa que, en tanto que unidad autónoma, es decir, organizacional, puede reaccionar a su entorno sólo de acuerdo con su propio modo de operación, su peculiar modo de operación. Debido a que el modo específico de operación de la sociedad es la comunicación, ésta no puede reaccionar al entorno de otra manera, y puesto que su entorno incluye todo aquello que no opera de un modo comunicativo, la sociedad es eo ipso, prevenida de comunicarse con el entorno. En cambio, ésta sólo puede comunicarse acerca de su entorno con ella misma. ${ }^{4}$

En efecto, Luhmann muestra cómo este concepto de autopoiesis puede extenderse al dominio de lo social al concebir a la sociedad como un sistema auto-reproductivo y a sus elementos constitutivos no como personas, papeles, instituciones, etc., sino como actos o eventos comunicativos. Los sistemas sociales se diferencian al constituirse auto-referencialmente, mediante el desarrollo de sus propios códigos de comunicación y sus medios de resolver la comple-

una semiótica de la cultura, una explicación análoga a la de Luhmann sobre la relación de la cultura hegemónica - la cultura de la globalización- con las culturas otras, basada en la dicotomía cultura/no-cultura, en donde esta última es considerada una especie de "naturaleza" respecto a la primera.

4 "Autopoiesis signifies the closure of a system's organization, i.e. the self-reference of the complex of components and component-producing processes that mutually reproduce themselves and thereby integrate and unify the system. Organizational closure does not mean that a system cannot be affected at all by its environment. But it does mean that, as an autonomous unity, i.e. organizationally, it can react to its environment only in accordance with its own mode of operation, the mode of operation peculiar to it. Because society's specific mode of operation is communication it cannot react to its environment in any other way - and since its environment includes everything that does not operate in a communicative way, society is eo ipso prevented from communicating with its environment. Instead, it can only communicate about its environment within itself " (Ecological Communication, xiii). 
jidad. "Todo lo que funciona como un elemento en el sistema es en sí mismo un producto del sistema" y, por lo mismo, "lo que no es comunicación es entorno para el sistema" (op. cit.: xi). Así pues, todo elemento del sistema es un elemento significativo, comprensible en el interior del código comunicativo propio del sistema. Los sistemas sociales tienen además la capacidad de observarse a sí mismos, la auto-referencialidad, de donde derivaría una conciencia de identidad social.

Esa propiedad autopoiética de los sistemas vivientes es entonces empleada para la explicación del carácter auto-referencial del sistema social, especialmente de la sociedad moderna, una sociedad con crecientes niveles de complejidad, la cual se organiza dentro de subsistemas especializados unifuncionales, como son la economía, la política, o la ciencia. Cada subsistema - y el sistema en su conjunto- funciona por tanto de acuerdo con su propio modo de operación y su propio código, el cual se rige por el principio de la diferenciación, basada ésta en el principio binario: lo legal y lo ilegal en el sistema jurídico, por ejemplo. A su vez, cada subsistema considera a los otros subsistemas como "entorno", y se relaciona con éstos convirtiendo sus elementos exógenos irritantes en asuntos de su propio lenguaje comunicativo, mediante lo que Luhmann llama resonancia. Es el caso de la irritabilidad producida por las denuncias del deterioro medioambiental, que el subsistema económico traduce en términos de precios. De allí que nuestro autor argumente que el carácter autopoiético del sistema social impide la comunicación con el entorno (sólo es posible la comunicación interna acerca del entorno). Sería entonces esta restricción comunicativa la raíz de los actuales problemas ecológicos y su mayor dificultad para resolverlos.

Ahora bien, lo que se aplica al entorno ecológico se aplica también a las sociedades que se encuentran "fuera" del sistema social, ya que necesariamente son tratadas como "entorno". En mi opinión, esta situación plantea tres posibilidades lógicas para estas sociedades otras: 1) permanecer fuera del sistema, en calidad de entorno, 2) irritar al sistema y provocar la resonancia y su consecuente traducción como tema comunicativo del sistema, o 3) buscar su asimilación al sistema, es decir, la disolución de su alteridad y su incorporación absoluta.

Como podemos observar, esto nos conduce a un modelo de sociedad moderna cerrada en su propia lógica de reproducción, aunque se plantee una apertura relativa tanto entre un subsistema y otro, como respecto al entorno por medio de la resonancia. Pero recordemos que ésta ocurre sólo como reacción a la "irritación", y se reduce a la conversión del objeto de irritabilidad en un elemento "significativo" del código comunicativo, lo cual significa que es una "apertura" y una cerrazón a la vez, pues en esas condiciones el objeto no se relaciona con el sistema de acuerdo con su propia lógica y naturaleza, sino ya como un elemento del sistema.

El poder de un modelo de sistema social de esta naturaleza puede ser muy efectivo en términos de su auto-reproducción, pero también es expansivo, y al- 
tamente destructivo, tanto del entorno ecológico como de las sociedades otras. Desde mi punto de vista, la importancia de conocer y discutir este modelo estriba en que efectivamente sintetiza la lógica y orientación de la sociedad moderna occidental, y al respecto podemos encontrar infinidad de ejemplos concretos. Baste recordar el fracaso de los esfuerzos de conservación del medio ambiente natural, el deterioro constante de las culturas indígenas en el mundo entero, las políticas del Banco Mundial y el Fondo Monetario Internacional, o la lógica de las guerras en Medio Oriente, para darnos cuenta de que no se trata de un modelo teórico cualquiera, sino de uno que se ha convertido en un poderoso paradigma que se encuentra en pleno funcionamiento. Es un modelo con el cual se construye una sociedad centrada en sí misma, que se relaciona y valora el mundo desde su propia posición e intereses, a costa de la posición e intereses del "entorno". En realidad, es la postura egoísta y totalitaria de la cual nos habla Levinas (1977) en su crítica a la filosofía predominante en Occidente. A fin de cuentas, debemos reconocer que no se trata de un modelo que dé cuenta de un sistema social cualquiera, sino de aquel que se ha instaurado en el mundo como dominante, que conceptualiza a todo lo demás como un entorno al que, según aquella lógica, no le resta sino convertirse en un elemento de su código comunicativo.

\section{La globalización}

Podríamos pensar que en su abstracción teórica Luhmann construye un tipo ideal extremo, pero que en realidad ni aun las llamadas sociedades modernas funcionan de acuerdo con el prototipo descrito. Sin embargo, lo interesante en todo caso es que el modelo en sí mismo tiene efectos concretos en la realidad social, al operar como un patrón, un poderoso instrumento organizativo de las sociedades de los países "altamente desarrollados", de sus instituciones, sus empresas y de toda suerte de agentes. En efecto, considero que una expresión concreta es aquel proceso surgido con la modernidad llamado globalización. Pasemos a considerar algunos de sus rasgos distintivos.

La globalización se ha vuelto un lugar común en las ciencias sociales y en infinidad de discursos públicos, al grado de que casi cualquier fenómeno social o cultural contemporáneo suele explicarse en términos de su "globalización". Panacea para algunos, maldición para otros, la palabra misma ha invadido el imaginario social, erigiéndose en referente obligado para la explicación del mundo, y funcionando en gran medida como un discurso redundante de acuerdo con el cual se es porque se es global. Una especie de tautología que alimenta la idea de un acontecimiento universal y positivo que, como si se tratase de un mandato divino, escapa a la voluntad humana y se presenta como destino para el mundo entero. Examinar el tema se vuelve importante justamente por eso, porque hay demasiadas ideas, creencias y relatos, que impiden tener la cla- 
ridad necesaria para el entendimiento de procesos que, en efecto, están alterando acelerada y radicalmente la sociedad y cultura contemporáneas, pero que, contrario a la imagen anterior, son una construcción ideológica, un modelo, con antecedentes históricos, con estados nacionales, empresas y organizaciones que lo impulsan, y con países, pueblos y personas que lo padecen. ${ }^{5}$

En principio, con el término globalización se evoca el tránsito a un nuevo tipo de integración de la población mundial, la inauguración de una sociedad libre, abierta; un proceso de cambio social denso y acelerado, caracterizado por la intensificación de flujos culturales en el marco de un sistema-mundo, edificado mediante novedosas redes de comunicación y del intercambio económico y cultural transnacional. Aunque esta imagen es tendenciosa, pues por un lado proyecta la idea de una ruta hacia la igualdad de las personas del mundo entero: "todos somos parte de la globalización, todos participamos en ella", y por el otro, presenta un trasfondo evolucionista de acuerdo con el cual "antes éramos locales, ahora somos globales", "antes premodernos, ahora absolutamente modernos".

Pero en realidad, "nosotros", "modernos", "globales", son palabras enunciadas desde determinado eje axiológico, que tienen como trasfondo un referente de contraste, de alteridad, una no-cultura, que no es moderna ni globalizada. ${ }^{6}$ Retomando la opinión de Appadruai (2002), vemos cómo el discurso hegemónico de la globalización proyecta una especie de "paisaje" de libertad y democracia, pero detrás de ese escenario optimista se esconden divisiones, desproporciones e inequidades, relaciones de dominación entre agentes y pacientes del proceso globalizador. En el mismo sentido, Featherstone (2002) señala que si bien en la superficie ocurren una integración, un mayor contacto entre la gente, un nuevo "flujo" de cultura, y hasta un "redescubrimiento" de etnicidades y un reconocimiento de la multiculturalidad, también es cierto que en gran medida ese reconocimiento se efectúa desde el eje del sistema social dominante, y a fin de cuentas la globalización, producto del sistema capitalista en su versión neoliberal, implica relaciones de dominación entre personas, estados y empresas trasnacionales. De donde resulta que en la vida real no todo el mundo se beneficie de ella ni la viva de igual manera. Según Jameson (2002), la globalización es en realidad un imperialismo cultural, fundamentalmente estadunidense, en cuya lucha por someter a su lógica a las culturas otras, genera tensiones y oposición, de manera que lejos de producirse el fin de las polaridades entre norte y sur, entre oriente y occidente, entre gente blanca y gente "de color", la globalización las reproduce y redimensiona.

\footnotetext{
${ }_{5}^{5}$ Para este tema he tomado importantes ideas del artículo de A. Appadruai en Criterios. Globalización cultural: Occidente/Oriente, Norte/Sur, núm. 33, La Habana, Cuba, 2002. Asimismo, es interesante la discusión de M. Augé (1996) acerca de los no-lugares y la sobremodernización en el mundo contemporáneo.

${ }^{6}$ Véase Sonesson (2002).
} 
Podemos plantear entonces que el discurso de la globalización corresponde a un modelo ideológico del sistema social dominante, y que este modelo se fundamenta en el concepto de autopoiesis teorizado por Luhmann.

\section{El sistema social y la identidad maya}

Ahora bien, si consideramos la situación actual de los mayas - o, para el caso, la de cualquier otro pueblo indígena - respecto a la modernidad y su modelo de globalización, no queda sino reconocer que para el sistema social dominante los indígenas son un "entorno". Sociedades "locales", "premodernas", a las cuales sólo les queda desaparecer o asimilarse, y eso en la medida que produzcan el ruido suficiente que los convierta en un tema de la comunicación auto-referencial, es decir, en una redundancia. Al igual que ocurre con el medio ambiente natural, las sociedades "otras" son un entorno carente de significado, pero del que se nutre, ciega y sordamente, el sistema. El viejo esquema marxista de desarrollo, medido en términos de explotación de la naturaleza, o la idea cristiana de la naturaleza al servicio del hombre, no parecen lejanos de la autopoiesis luhmanniana. De hecho, visto desde esa óptica, los mayas se encuentran en proceso de asimilación al sistema, por estar siendo progresivamente incorporados como tema de comunicación, particularmente en el interior del subsistema económico. El mercado turístico del megaproyecto empresarial denominado Mundo Maya, el uso generalizado y comercio de imágenes de los mayas, de reliquias mayas en libros, videos, documentales, cine, etc., el mercado de piezas arqueológicas y de "arte maya", son clara muestra de la manera como esta cultura está siendo asimilada al sistema, y el lugar que éste le confiere en su estructura. Es más, podríamos pensar que la relación de gran parte de la actividad científica del mundo occidental respecto a las culturas indígenas se encuentra orientada en ese sentido: una incorporación de la alteridad cultural mundial al logos universalista de Occidente. Me pregunto si en el fondo no es eso lo que significa el novedoso discurso de la multiculturalidad, un aparente "diálogo" entre culturas, pero orquestado esencialmente desde el eje del poder dominante y en función de sus fines. ${ }^{7}$

Por otro lado, esta semantización de los mayas y su cultura por parte del sistema social dominante se encuentra reflejada en el plano de su identidad étnica. La relación de los mayas con la globalización es un caso extremo que ilustra precisamente cómo el fenómeno de la identidad no se fundamenta en esencias inalterables, inmutables en el tiempo, ni sólo en una conciencia de sí (la autoreferencia), sino que esa identidad consiste en constructos ideológico-cultura-

\footnotetext{
${ }^{7} \mathrm{Al}$ respecto, Augé advierte sobre los riesgos de un enfoque culturalista de las sociedades: "el respeto de las diferencias, el derecho a la diferencia, la noción de sociedad pluricultural, pueden proporcionar el lenguaje noble y la coartada de una ideología del gueto y de la exclusión" (1996: 99).
} 
les en los que participan tanto el grupo social o étnico de que se trate, como las alteridades con las que el grupo se relaciona. Esto quiere decir que la identidad se construye en íntima relación con la alteridad, en el proceso de las relaciones yo-otro. En el caso que nos ocupa, la identidad maya, independientemente de los procesos internos de autodefinición, está activamente construida desde la exterioridad de la otredad dominante, desde el eje axiológico del sistema y su proyecto de globalización.

\section{Identidad dialógica maya}

Cuentan que el Sol es nuestro padre. Y la Luna nuestra madre.

Demos ahora un paso adelante y preguntemos ¿qué ocurre si partimos del concepto de sistema social para concebir a los mayas como una sociedad en el sentido de Luhmann ${ }^{8}$ Los mayas se encuentran organizados en grupos étnicos distintivos, con idiomas, economías, rituales y muchos otros rasgos culturales propios, además de códigos comunicativos y subsistemas, que confieren a cada grupo la condición de sociedad. Sociedades rurales, en su mayoría, que encuentran en su propia cultura los códigos comunicativos y modos de operación necesarios para su auto-reproducción. Considero a la lengua como un poderoso medio de comunicación que permite dentro de un sistema social la auto-referencialidad, es decir, la capacidad de pensarse a sí mismos y pensar el entorno.

Podemos preguntarnos entonces cómo los mayas, entendidos como un sistema social particular, se relacionan consigo mismos y con su entorno: el natural y el social, incluyendo en este último a la sociedad moderna y la globalización. La respuesta a esta pregunta podría acercarnos a la comprensión de la identidad maya en su intrínseca relación con la alteridad, sobre todo con la sociedad dominante. Además es interesante porque permite poner a prueba la teoría del sistema social, y quizá, como ejemplo divergente, revertiría la perspectiva hegemónica del sistema social dominante.

Consideremos algunas referencias antropológicas. Un rasgo ampliamente documentado por la investigación mayista es que la concepción del mundo de los mayas actuales es de carácter inclusivo, ya que imagina al hombre como parte de la naturaleza, situándose en el interior del entorno, y no fuera y desligado de él. Es decir, en contraposición con la perspectiva de exclusión, que establece la absoluta división entre sociedad y naturaleza, los mayas se entienden

\footnotetext{
8 "Society: That social system which includes all meaningful communication and is always formed when communication takes place in connection with earlier communication or in reference to subsequent communication (i.e. autopoietically)" (Luhmann, op. cit.: 146).
} 
a sí mismos con el entorno, construyen su identidad en íntima relación con un complejo de alteridades naturales, sociales y culturales que los circunda. Es reveladora en este sentido la afirmación reiterada de los pueblos mayas acerca de ser "verdaderos", "legítimos", "originarios". Se trata de pensarse a sí mismos como hijos de la tierra, brotados de ella, 'propios del lugar', así como lo son las plantas y los animales. Para ellos la tierra es un ser vivo, una entidad simbólica muy compleja, una alteridad vivida como madre, fuente del sustento vital, y políticamente es su territorio.

Otra de esas importantes continuidades que destacan por encima de las múltiples transformaciones de su cultura y sociedad es la manera como los mayas interactúan con su medio natural. Su relación con la tierra -la Madre Tierra-. la montaña sagrada, las cuevas y la agricultura es reflejo de sus principios axiológicos, en el fondo religiosos, y la base de su reclamo de territorialidad étnica, pero también de un pensamiento ecológico que hoy en día se plantea como una propuesta alternativa de relación con el medio, de la cual se nutre el movimiento conservacionista mesoamericano. ${ }^{9}$

En la tradición oral contemporánea se conserva viva esa "cosmovisión" maya como un reservorio de conocimientos y percepciones culturales; en ella se recoge una reflexión filosófica sobre el mundo y el ser humano, donde entre muchos otros temas se discuten los enigmas de la identidad humana. A diferencia del pensamiento predominante en Occidente, en el que la identidad de una persona o grupo social se define en términos de su mismidad, del eje egocéntrico, en la auto-referencialidad, los mayas parten de la unión indisoluble entre humanidad y naturaleza, es decir, parten de la relación complementaria entre identidad y alteridad. En efecto, en la perspectiva indígena, una parte del ser se encuentra fuera de sí mismo, se encuentra justamente en el exterior, en el entorno. La apariencia de una persona es entendida así, como un aspecto, como una imagen externa y visible, mientras que la otra parte del ser, la más interesante y enigmática, permanece oculta. Es por cierto en este aspecto de la personalidad donde se centra la reflexión y la especulación cotidiana. Se trata de una alteridad que es parte sustancial del ser, una alteridad que en el pensamiento maya se ubica en el mundo de la naturaleza. El rayo, el viento, el jaguar, o el coyote, entre tantos otros, conforman esa alteridad inherente a la personalidad del individuo y de las comunidades. Cada pueblo, cada aldea, por ejemplo, cuenta con sus cerros sagrados, y desde la Colonia, con sus santos patronos. Es más, toda entidad existente en el mundo indígena tiene un aspecto espiritual, sagrado, tiene nagual o ch'ulel.

\footnotetext{
${ }^{9}$ La crítica referente a que los mayas son los principales agentes de la destrucción de las selvas en Guatemala y Chiapas debe ser ponderada en su justa dimensión. Hay que reconocer de entrada que tanto su crecimiento demográfico como la "expansión de la frontera agrícola" son consecuencia directa de las políticas de sus gobiernos y de agencias internacionales, es decir, son producto de las acciones "sistémicas" de los poderes dominantes respecto del "entorno".
} 
Este es un tema que la etnología especializada ha estudiado extensivamente y consignado bajo el término de nagualismo.

Considerable cantidad de registros etnográficos documenta esa espiritualidad maya. En particular es interesante aquello que se ha traducido como "alma". ${ }^{10}$ Se trata de una dimensión espiritual muy amplia del mundo maya, una filosofía, y más concretamente una ontología, de acuerdo con la cual las cosas del mundo, incluyendo los seres vivos, poseen un componente espiritual. Esta idea se encuentra en el centro del concepto maya de persona, y vincula lo humano con otro componente natural y sagrado. Pitarch, autor de una etnografía especializada sobre las "almas" tzeltales, reconoce en el concepto ch'ul la raíz linguística de 'lo sagrado', pero argumenta que es a la vez un marcador de alteridad: ch'ul es "lo otro del ser" (1996: 32). De allí que este autor plantee que la persona indígena es una reunión de fragmentos heterogéneos, una heteróclita conjunción de seres, lugares y tiempos (op. cit.: 99).

Esta enigmática idea del ch'ul se encuentra muy presente, casi de manera obsesiva, en la narrativa tradicional maya, y constituye sin duda un referente constante de la vida cotidiana. De mis largas estancias en poblados ch'oles de la sierra norte de Chiapas en los años ochenta y noventa, recuerdo cómo la incógnita acerca del "alma" de las cosas, de los seres del mundo y de la gente en particular, era una preocupación constante, o al menos un tema de reflexión cotidiano entre la gente. Especular sobre el wäy de una persona me ha parecido una especie de juego de lenguaje de los ch'oles, al cual se podía volver una y otra vez, sin que el propósito de fondo fuese desvelar al fin ese aspecto escondido y misterioso de la persona, sino que más bien se trataba de dar vueltas interminables en torno a un tema enigmático, el cual a fin de cuentas debía quedar en el misterio.

La narrativa ch'ol tradicional tiene como uno de sus temas fundamentales las relaciones del nosotros indígena con la alteridad, es decir, con esa vasta dimensión natural, humana, social, ideológica y religiosa, con la que ese nosotros se relaciona y de la cual depende la vida misma. Y es que para los mayas, y los indígenas mesoamericanos en general, la identidad de la persona o del grupo no se entiende unilateralmente en términos de lo propio, de un conjunto de rasgos distintivos, sino que se trata de un fenómeno intrínsecamente relacional. Pero debe aclararse que esa identidad étnica no se limita a las relaciones del grupo con otros grupos étnicos, por ejemplo con los kaxlanes, ${ }^{11}$ término dado a los europeos y la gente asociada a estos, pues, además de esas corres-

\footnotetext{
${ }^{10}$ El estudio de Pitarch sobre las almas tzeltales (1996) es ilustrativo al respecto. Véase también Petrich (2003: 577 y ss.) y Alejos García (1994: 411-418). Existe una diversidad de estudios sobre espiritualidad maya, en particular centrados en el tema del nagualismo.

${ }^{11}$ Empleo esta categoría indigena que nombra a todo aquel que no es indígena y se asocia a la cultura occidental. La palabra tiene su origen en el vocablo "castellano" del siglo xvi, y su uso se encuentra muy extendido en el área mesoamericana.
} 
pondencias sociales, también existen relaciones con entidades de otro orden, como lo es la Madre Tierra, ${ }^{12}$ o con la otredad ch'ul, es decir, con el mundo de la naturaleza y con las divinidades. Por otro lado, el fenómeno identitario también es relativo, pues los planos de las relaciones nosotros-los otros son diversos, y cambian según las circunstancias concretas. En este sentido, podemos decir que la concepción maya del mundo es "relativista", y cuestiona el pensamiento racional y positivista predominante de Occidente. Se trata de una concepción "no-euclidiana" del mundo, que encuentra una "cuarta dimensión" en los objetos y en los seres vivos, y por lo mismo, una concepción difícil de comprender para nosotros los kaxlanes. Esto lo podemos ver en los abundantes intentos antropológicos de "explicar el nagualismo" en términos racionales, recurriendo para ello a conceptos como el de función, control social y creencia, entre otros.

La orientación inclusiva de los mayas respecto a la alteridad se pone de manifiesto en el complejo de sus lazos interétnicos. Aparte de las relaciones entre los pueblos indígenas, desde hace ya casi 500 años los mayas han mantenido una intensa relación con los europeos y su descendencia mestiza, es decir, con los kaxlanes. La adopción constante de la cultura del otro, así como el mestizaje, dan cuenta del comportamiento de los mayas con la alteridad étnica. La globalización, desde la perspectiva indígena, tiene como antecedente esa vieja historia de colonialismo europeo y norteamericano; es la nueva versión de un sistema de dominación, frente al cual los mayas contestan con sus propios recursos culturales e ingenio; se abren al cambio y se apropian de la cultura ajena, más que cerrarse en su interioridad, aunque esto lo hagan en franca posición de desventaja e inequidad.

Veamos lo que nos dice Pitarch respecto a la vitalidad cultural de los mayas de Cancuc:

En contraste con muchos otros pueblos colonizados, que no consintieron en su subordinación política inmediata ni aceptaron el cristianismo en un primer momento, pero luego fueron radicalmente transformados (o aniquilados) a causa de su relación con los europeos, los cancuqueros parecen representar el caso opuesto. Un pueblo que se sometió a la Corona sin dilación y aceptó (nominalmente) el cristianismo y con él la política de reducción y la administración europea, pero que, no obstante, al cabo de varios siglos preserva una existencia cotidiana esencialmente amerindia. En una situación así —un movimiento simultáneo de integración y diferenciación, de acomodo tácito al orden impuesto, pero no a la lógica que lo justifica-, los cancuqueros debieron hacer uso de las instituciones virreinales y más tarde republicanas, hasta el presente, tratando de emplearlas en beneficio propio (1996: 167-168).

\footnotetext{
${ }^{12}$ Las investigaciones etnográficas han aportado abundante información sobre la íntima relación del ser humano con la tierra, presentándola como fundamento del sentido de territorialidad étnica maya. Este rasgo es compartido con muchos otros grupos étnicos del mundo.
} 
Algo que me parece importante destacar de esta estrategia de cambio es cómo la adopción de la cultura ajena se hace con el fin de preservar la cultura propia, lo cual evidencia una actitud de apertura por parte de los indígenas frente a la cultura otra, una intención de acercamiento y de aprendizaje del otro, y en general la búsqueda de un diálogo a partir de un conocimiento y entendimiento exotópicos de la alteridad. En todo caso, el problema es que esta empatía hacia Occidente se topa con la indiferencia propia de la autopoiesis del sistema social dominante, que arrasa con la diferencia cultural en su obsesión por simplificar la complejidad.

\section{Conclusiones}

Una lección que podemos rescatar de la manera como construyen los mayas su "sistema social" y de allí su sentido de identidad, es su orientación inclusiva. Esto nos lleva a cuestionar el concepto de identidad como un fenómeno particularmente egocéntrico, de auto-referencialidad, que se relativiza al introducir la categoría del otro como elemento constitutivo de la identidad del nosotros, es decir, vincula la identidad a la alteridad, a manera de aspectos complementarios más que excluyentes.

Podemos plantear que en general los sistemas sociales no son sólo autoreferenciales, sino que también comportan un carácter dialógico. No tratan al entorno como algo absolutamente externo, sino que pueden interactuar con éste de manera más o menos abierta, sin tener que aprehenderlo al logos del sistema. En todo caso, la teoría de sistemas de Luhmannn sí da cuenta de la orientación ideológica del sistema social dominante, cuyo afán de poder lo hace cerrarse sobre sí mismo y tratar al otro como entorno indiferenciado e insignificante. Como ya he señalado, la devastación ecológica y la decadencia de las culturas indígenas es evidencia de esta patología del poder.

Otra lección que podemos tomar de nuestra lectura de Luhmann es que el sistema reacciona y puede cambiar en la medida en que se produzca el ruido suficiente para romper con el aislamiento autopoiético. En otras palabras, hay que hacer ruido, para ser escuchados. Pero quizá no se trate del tipo de ruido que pueda anticipar el sistema, sino que deba generarse un discurso capaz de romper con la lógica del sistema, que inaugure un verdadero diálogo intercultural y modos alternativos de convivencia con las otras culturas y con el medio ambiente natural.

Hasta ahora la perspectiva de la modernidad para los pueblos mayas se reduce a los planes desarrollistas de una versión tercermundista de globalización, la cual proyecta la construcción de grandes autopistas para atravesar los remanentes de selvas, y de aeropuertos y hoteles, contiguos a grandes ciudades arqueológicas, para el desplazamiento y confort del "gran turismo". Además de la apertura a inversiones extranjeras en maquilas, la explotación de hidrocarburos 
y la construcción de hidroeléctricas, como las proyectadas para el río Usumacinta, ${ }^{13}$ y tantos otros planes de "desarrollo" cuya finalidad es aprovechar las "ventajas comparativas" que "ofrecen" nuestros países, es decir, los recursos naturales, la mano de obra barata y en breve, el remate de los bienes nacionales. Los mayas son, a fin de cuentas, entorno, pensado, aprehendido en función de los intereses del sistema. Son "mundo maya", objeto construido por el subsistema económico como mercancía que se vende en el mercado internacional.

Como ya hemos señalado, los antecedentes históricos de la situación actual se remontan a la situación colonial vivida por los pueblos indígenas americanos, en gran medida una historia de desencuentros, malentendidos y choques, muchas veces violentos. De allí que las relaciones entre las culturas indígenas y la sociedad nacional, y ahora con la globalización, se hayan caracterizado por una profunda incomprensión, una falta de respeto de la cultura dominante hacia las culturas otras, evidente en el desprecio y racismo prevalecientes.

Es innegable que en la actualidad los pueblos indígenas participan en espacios de interacción y comunicación local, nacional y mundial, beneficiándose de avances tecnológicos, del acceso a nuevos mercados y de cierta apertura democrática, pero también es cierto que esto ocurre en condiciones de franca desventaja. En realidad, los niveles de exclusión y desigualdad sociales son graves; pocos son los mayas que hoy en día tienen acceso a los recursos que ofrece el modelo de globalización. Considero que en nuestros países el balance es más bien negativo, al ensanchar la brecha entre ricos y pobres, entre conectados y marginados, entre quienes tienen los medios para enriquecer su cultura propia y los que se ven orillados a abandonarla. Por otro lado, la apertura a la globalización entraña, como hemos visto, el riesgo de exponer el patrimonio nacional, los recursos naturales y los conocimientos y propiedades de los pueblos indígenas a la voracidad de los intereses externos. Para el caso de los pueblos mayas, la versión más cercana de la globalización es el tristemente célebre Plan PueblaPanamá, propuesto por la actual administración del gobierno mexicano.

De las consideraciones anteriores, podemos señalar la profunda inequidad de la integración de los pueblos indígenas a la llamada "economía-mundo". Nos queda claro que el beneficio de ese proceso lo reciben principalmente los agentes de los nuevos estados imperiales. Los "flujos culturales" que elogian algunos teóricos, son más bien unívocos, y representan nuevas modalidades del ejercicio de dominación. El encuentro entre personas del mundo entero podrá ser intenso, pero es sólo un hecho superficial, porque en el fondo tales encuentros se dan en situaciones de mucha desigualdad. En breve, la globalización produce más bien un ensanchamiento de la brecha entre ricos y pobres, dejando sin resolver problemas "globales" que están haciendo del mundo un lugar cada vez más violento y alienado.

\footnotetext{
${ }^{13}$ Sobre el tema, véase el interesante estudio de Wilkerson (1986).
} 
Las continuidades y cambios en la identidad de los mayas son resultado de una larga y tensa relación con la sociedad nacional y con el mundo globalizado. Negociaciones, reacomodos y defensa de la vida y la cultura, que se magnifican en el presente. Me queda claro cómo en el futuro los mayas deberán continuar esa lucha histórica por su cultura y patrimonio, para ser escuchados y hacer avanzar sus propios intereses en medio de un ambiente globalizado y hostil. Nuestro lugar como estudiosos de la cultura en este contexto es relevante, pues como bien reconoce Luhmann, el subsistema educativo tiene una especial capacidad de resonancia (op. cit.: 104). Quizás el reto para nosotros consista en lograr desactivar el dispositivo autopoietico del sistema dominante.

\section{BIBLIOGRAFÍA}

Alejos García, José O.

1988 Wajalix bä t'an. Narrativa tradicional ch'ol de Tumbalá, Chiapas. México: UNAM, IIFL, Centro de Estudios Mayas.

1994 "Magia y razón. Antropología del nagualismo en Mesoamérica", en Anuario del Instituto Chiapaneco de Cultura 1993, pp. 411-418. San Cristóbal de Las Casas: Instituto Chiapaneco de Cultura.

1998 "Identidades negadas. Etnicidad y nación en Guatemala", en La construcción de la nación y la representación ciudadana en México, Guatemala, Perú, Ecuador y Bolivia, pp. 247-271, C. Dary (comp.). Guatemala: FLACSO.

Anderson, Benedict

1993 Comunidades imaginadas. Reflexiones sobre el origen y la difusión del nacionalismo, México: FCE.

Appadruai, Arjun

2002 "Disyunción y diferencia en la economía cultural global", Criterios. Globalización cultural: Occidente/Oriente, Norte/Sur, 33: 13-41. La Habana, Cuba.

Augé, Marc

1996 El sentido de los otros. Actualidad de la antropología, Barcelona: Paidós.

De Vos, Jan

1999 "Los mayas en los tiempos modernos", en Los mayas, pp. 495-505, Peter Schmiedt, Mercedes de la Garza y Enrique Nalda (coords.). México: CNCAINAH/Américo Arte Editores.

Featherstone, Mike

2002 "Culturas globales y locales", Criterios. Globalización cultural: Occidente/Oriente, Norte/Sur, 33: 69-93. La Habana, Cuba. 
Fiedman, Jonathan

2002 "Globalización, clase y cultura en los sistemas globales", Criterios. Globalización cultural: Occidente/Oriente, Norte/Sur, 33: 156-179. La Habana, Cuba.

García Canclini, Néstor

1990 Culturas hibridas. Estrategias para entrar y salir de la modernidad. México: Grijalbo.

Gellner, Ernest

1991 Naciones y nacionalismos, México: CNCA / Alianza Editorial.

Jameson, Fredric

2002 "Notas sobre la globalización como cuestión filosófica", Criterios. Globalización cultural: Occidente/Oriente, Norte/Sur, 33: 42-68. La Habana, Cuba.

Levinas, Emmanuel

1977 Totalidad e infinito. Ensayo sobre la exterioridad. Salamanca: Ediciones Sígueme.

Luhmann, Niklas

1989 Ecological Communication. Cambridge: Polity Press.

1991 Sistemas sociales. Lineamientos para una teoría general. México: Alianza Editorial/Universidad lberoamericana.

Petrich, Perla

2003 "Topología nocturna en los pueblos mayas de Atitlán", en Espacios mayas, pp. 577-601, Alain Breton et al. (eds.). México: UNAM/CEMCA.

Pitarch, Pedro

1996 Ch'ulel. Una etnografia de las almas tzeltales. México: FCE.

Sonesson, Göran

2002 "Dos modelos de globalización", Criterios. Globalización cultural: Occidente/ Oriente, Norte/Sur, 33: 107-134. La Habana, Cuba.

Wilkerson, Jeffrey

1986 "Damming the Usumacinta: the archaeological impact", Sixth Palenque Round Table, 1986, pp. 118-134, M. Greene Robertson (ed.). Oklahoma: University of Oklahoma Press, Norman y Londres. 